\title{
A new methodology for examining the efficacy of SBIRT protocols on reducing healthcare utilization and costs
}

\author{
Janice Pringle ${ }^{1 *}$, Arnie Aldridge ${ }^{2}$, Shannon Kearney ${ }^{1}$ \\ From INEBRIA 12th Congress, \\ Atlanda, GA, USA. 24-25 September 2015
}

\section{Background}

There is increasing interest in deploying Screening, Brief Intervention, and Referral to Treatment (SBIRT) practices in emergency departments (ED). However, the current literature is inconclusive on whether or not SBIRT practices are cost effective and cost beneficial. In order to answer this question, new analytical methods need to be developed.

The objective of the following study was to pilot a new experimental methodology - modeling costs using a multilevel generalized linear model (GLM) - for studying the impact of SBIRT on healthcare utilization and costs.

\section{Material and methods}

In the study, healthcare utilization and costs were quantified for patients who received emergency department (ED) services and participated in an SBIRT program entitled Safe Landing. The healthcare and utilization costs of patients who underwent the Safe Landing program were compared using a multilevel GLM to patients in three control groups where no SBIRT protocol was implemented.

the reduction in health care costs was driven mainly by a decrease in inpatient visits.

\section{Conclusions}

This study provides further support that SBIRT programs are a cost-effective and cost-beneficial approach to substance use disorder management. The study also contributes to important literature on the impact of SBIRT implemented in real world settings, rather than traditional randomized clinical trials.

\section{Authors' details}

${ }^{1}$ School of Pharmacy, Department of Pharmacy and Therapeutics, University of Pittsburgh, Pittsburgh, USA. ${ }^{2}$ RTI International, Research Triangle Park, USA.

Published: 24 September 2015

doi:10.1186/1940-0640-10-S2-O44

Cite this article as: Pringle et al:: A new methodology for examining the efficacy of SBIRT protocols on reducing healthcare utilization and costs. Addiction Science \& Clinical Practice 2015 10(Suppl 2):044.

\section{Results}

The study found that SBIRT was associated with $24 \%$ lower health care costs from the 12 months preceding the index ED visit to the 12 months following the index ED visit. This translates to approximately $\$ 2,600$ per patient per year. This reduction in healthcare costs could be linked mainly to decreased inpatient use. The study found a reduction in inpatient claims and visits, suggesting that

\footnotetext{
* Correspondence: jlpringle@pitt.edu

${ }^{1}$ School of Pharmacy, Department of Pharmacy and Therapeutics, University of Pittsburgh, Pittsburgh, USA

Full list of author information is available at the end of the article
}

Submit your next manuscript to BioMed Central and take full advantage of:

- Convenient online submission

- Thorough peer review

- No space constraints or color figure charges

- Immediate publication on acceptance

- Inclusion in PubMed, CAS, Scopus and Google Scholar

- Research which is freely available for redistribution 